\title{
Analysis of Sequential Explanatory of Teacher's Performance Reviewed from Transformational Leadership, Job Engagement, and Interpersonal Communication
}

\author{
Kun Nurachadijat, Soewarto Hadhienata, Widodo Sunaryo \\ Post Graduate Program, Universitas Pakuan Bogor, Indonesia
}

*Corresponding Author: Kun Nurachadijat, Post Graduate Program, Universitas Pakuan Bogor, Indonesia.

\begin{abstract}
This study aims to reveal and analyze the sequential explanatory teacher performance concerning transformational leadership, job involvement, and interpersonal communication. This research is done by survey method with the target population is all of the Foundation's permanent teachers as many as 113 people selected in proportional random sampling spreading out in 10 High Schools in Bogor City, West Java, Indonesia. The hypothesis test was conducted at the level of significance 0.05. Using Sequential Explanatory Mixed Methods, this research concludes that there is a very significant positive relationship reinforced by quantitative research results that transformational leadership affects teacher performance with correlation coefficient $=0.801$ and coefficient of determination $=0.791$. Also job involvement affects teacher performance with correlation coefficient $=0.706$ and coefficient of determination $=0.684 \mathrm{c}$ and interpersonal communication affects teacher performance with coefficient $=0.755$ coefficient of determination ry32 $=$ 0.697. Finally, together transformational leadership, job engagement and interpersonal communication affect teacher performance with correlation coefficient $=0.706$ and coefficient of determination $=0.598$.
\end{abstract}

Keywords: Teachers performance, transformational leadership, job engagement, and interpersonal communication

\section{INTRODUCTION}

Improving the quality of education should be supported by the existence of human resources capable of performing their primary duties and functions optimally and professionally. This condition is reinforced by Indonesian law no. 14 of 2005 on teachers and lecturers stating that teachers must have the ability to realize the goals of national education. Nevertheless, the reality of the field is still found the low quality of work of teachers both at the level of primary and secondary schools.

Teacher performance is the contribution made by the teacher in achieving the purpose of the school in which he is in charge. The quality of teacher performance determines the quality of educational outcomes because the teacher is a party that many directly in contact with students in the learning process in school. So it is clear that teacher work can not be done by just anyone without having the skills and qualifications as a teacher.

This study attempts to examine the phenomenon that occurs in high school teachers which in general there is a tendency of teachers to teach only as a routine without the creativity and innovation of development that has not been able to create an active learning atmosphere, creative and fun. During this time teachers seem less motivated to perform high and pay less attention to the aspects of serving the needs of students, so it can not be realized as a teacher helping students.

Objective conditions were obtained from a preliminary survey on 2 (two) private high schools outside the population of 33 teachers with six indicators including Lesson Planning, Learning Evaluation, Collaboration, Creativity, Work Effectiveness, Decision Making, resulted in a conclusion:

1. 86.36\% of teachers have problematic regarding making lesson planning, especially on preparing annual programs and semesters before the implementation of teaching and learning activities and educators make bank questions to facilitate the education and learning activities.

2. $71.21 \%$ of teachers have problem in terms of making education evaluation, especially in carrying out pre-test before teaching and learning activities and educators play activity assessment based on the cognitive, affective, and psychometric sphere. 
3. $66.67 \%$ of teachers have a problem in cooperation to discuss issues faced by students with principals, parents or other competent parties. Teachers present difficulties encountered in school with administrators and other teachers.

4. $77.27 \%$ of teachers problematic have problems in terms of creativity, especially on preparing remedial materials at the beginning of the school year for students who have not reached the minimum passing criteria and teachers held student's ability test at the start of the semester before starting teaching.

5. $77.61 \%$ performance of teachers have problems in terms of effectiveness of work, especially on teachers having the target of work in every activity and teachers finish the work on the time determined.

6. $75.76 \%$ of teachers have problems in terms of decision-making, in particular on the implementation of decisions following the authority and responsibility and consulting the decision with the principal.

Based on the preliminary survey, it is predicted that if the transformational leadership is high, then the performance of the teacher will increase because transformational leadership can blend self-interest from the teacher into the common interest so that the fulfillment of the teacher as a whole can be conditioned. In the other hand, job engagement realizes that success in work is the teacher's honor making it is possible to be a driver of high-performance achievement. On the contrary, the cohesive interpersonal communication, the vision of the school's mission represented by the principal's application will be transferred, so that teachers with high awareness can achieve peak performance. In other words, outstanding interpersonal communication creates a transfer of knowledge, and the transfer of knowledge is very efficient.

Thus, it is strongly suspected that high teacher performance is largely determined by the extent to which the influence of transformational leadership, job engagement, and interpersonal communication is applied in an educational institution. This is why, the power of Transformational Leadership, Job Engagement and Interpersonal Communication on teacher performance becomes an interesting research object, especially for private high school teachers in Bogor City.

\section{MATERIALS AND MeTHODS}

This study used Mixed Methods, which is a research method that combines quantitative and qualitative methods to be used jointly in a research activity so that more comprehensive, valid, reliable and objective data are obtained. Creswell classifies mixed methods into two models: sequential model (consecutive combination) and concurrent model (mixed combination). The sequential model consists of Sequential Explanatory Design, Sequential Exploratory Design, and Transformative Design. While the parallel example (mixed combination) consists of Concurrent Triangulation Design, Concurrent Embedded Design and Concurrent Transformative Design (Sugiono, 2013). This study applies Sequential Explanatory Design Mixed Method where quantitative research is ahead of the qualitative study to examine the relationship between variables tested in the survey using three independent variables through data obtained from questionnaires. The independent variable is Transformational $\left(\mathrm{X}_{1}\right)$, Job Engagement $\left(\mathrm{X}_{2}\right)$, and Interpersonal Communication $\left(\mathrm{X}_{3}\right)$, while the dependent variable is the Teacher's Performance(Y).

The population is a generalization region consisting of objects or subjects that have certain qualities and characteristics determined by the researcher to be studied and then drawn a tentative conclusion. The study population is the Permanent Teacher of Private High School Foundation of Bogor City, West Java Province. Samples are part of the number and characteristics possessed by the population. Sampling in this research by using the technique of proportional random sampling. The number of samples used for the trial as many as 30 people outside of the 156 permanent teachers of Yayasan from private high schools in the area of Bogor City West Java Province as a sample of 113 teachers. The target of qualitative research is taken 3 (three) schools based on upper, middle and lower category. Qualitative study for confirmation was performed through observation and interview to the key informant as well as conducting focus group discussion with the school principals. 


\section{RESULTS AND DISCUSSION}

The results of hypothesis testing show that there is a functional relationship between transformational leadership with teacher performance with regression equation $\hat{Y}=0.841+0.798 \mathrm{X}_{1}$ showing a positive relationship between transformational leadership and teacher performance. The coefficient of determination between transformational leadership and teacher performance is 0.641 . This means that $64.1 \%$ teacher performance is the result of the work of transformational leadership variable, while $35.9 \%$ is contributed by other variables that are related to Teacher Performance improvement. The findings obtained in this study indicate that Transformational Leadership is a reference to improve teacher performance through 1) charisma, that is leadership attribute based on individual personality quality, (2) influence to followers mindset, that is role model in work, (3) inspiration that motivates, that is encouragement or enthusiasm in work, (4) intellectual stimulation, that stimulates the growth of new innovation, (5) individual attention, that is giving support or spirit to subordinates.

The above quantitative data is reinforced by the observation results data on qualitative research that have conclusions about transformational leadership is that transformational leadership in each school observed has a different character pattern according to the direction cast by the principal.

According to Bernard M. Bass and Ronald E. Riggio (2006), transformational leadership stimulates and inspires followers to achieve great results and in the process of developing their leadership capacity. The factors are: (1) The leader acts as a role model or role model (Idealized influence). (2) The manager creates a clear picture of the future state optimistically (Inspirational motivation). (3) Leaders stimulate people to be creative and innovative (Intellectual simulation). (4) Leaders develop people by creating a supportive weather environment (Individual consideration).

Transformational leadership should be a reference for principals in performing tasks as leaders in schools, especially in addressing external factors that may affect personal and organizational performance. Thus a headmaster who has a visionary, transformational leadership will be able to improve the performance of his teachers. Previous research has also proved that transformational leadership has a positive relationship with teacher performance, one of them is Lulus Triwahyuni, Thamrin Abdullah, and Widodo Sunaryo (2014) on the relationship between transformational leadership and teacher performance, expressing the correlation coefficient of 0.641 . This figure indicates the relationship between transformational leadership with teacher performance has a positive and significant association. Thus this relevant research supports the results of current research.

Based on the above description can be concluded that the higher the transformational leadership, the higher the performance of teachers, and vice versa, the lower the transformational leadership, the lower the performance of the teacher. Thus the findings of facts and data in the analysis of this study further support the earlier findings of a positive relationship between transformational leadership and teacher performance.

The result of hypothesis testing shows that there is a functional relationship between job engagement with teacher performance with regression equation $\hat{\mathrm{Y}}=0.704+0.832 \mathrm{X}_{2}$. This shows a positive correlation between job engagement and teacher performance.

The above quantitative data is reinforced by the observation data on qualitative research that has conclusions that the involvement of workers in every school observed has the same characteristic pattern according to the specificity of the environment so that the qualitative work involved in the field has the same tendency with the quantitative result.

The findings obtained in this study indicate that the teacher's responsibility can influence the function and task of the teacher in improving the teacher's performance in the organization because the teacher's involvement will form the personality characteristics of the teacher in managing and developing the competence to improve its performance.

This is consistent with the theory put forward by Stephen P. Robbins (2013) that job involvement is to what extent a person identifies with his work, actively participates in it and considers his or her appearance essential to self-esteem.

Previous relevant studies have proven that job engagement has a positive relationship with the performance of teachers, such as the study of Muhammad Rizwan, Dil Jan Khan, and Fawad Saboor 
(2011). The results of this study show the relationship of both variables correlation coefficient value of 0.67. This finding shows the relationship between job engagement and performance has a positive correlation that the results of this relevant study reinforce the results of current research. This means that the higher the involvement of work, the higher the performance of teachers, and vice versa, the leverage of job engagement the lower the performance of teachers, thus the fact finding and the data in this analysis increasingly support the previous conclusions of a positive relationship between engagement work with teacher performance.

The result of hypothesis testing shows that there is a functional relationship between interpersonal communication with teacher performance with regression equation $\hat{Y}=0.665+0,842 X_{3}$. This shows a positive relationship between interpersonal communication and teacher performance.

The coefficient of determination between interpersonal communication and teacher performance is 0.57 . This means that $57 \%$ of teacher performance is the result of the workings of interpersonal communication variables, while $43 \%$ is contributed by other variables that are related to teacher performance improvement.

The above quantitative data is reinforced by the observation data on qualitative research which has the conclusion that interpersonal communication in every school observed has the same character pattern according to the specificity of the environment so that the qualitative research results in the field have the same tendency with the research result quantitative.

This is reinforced by the theories of Steven L., McShane and Mary Ann Von Glinow (2010) concluded that effective interpersonal communication depends on the sender's ability to get the message across and the recipient's performance as an active listener. Previously relevant research results have also proved that interpersonal communication has a positive relationship with teacher performance, one of which is the study of A. Kadir, Bibin Rubini, and Thamrin Abdullah (2016). The results of this study indicate the correlation value of Interpersonal Communication with Teacher Performance of 0.681 . This figure shows that Interpersonal communication with teacher performance has a positive and significant relationship that the relevant research results strengthen the results of current research.

This result means that the higher the achievement of interpersonal communication the higher the performance of teachers, and vice versa, the lower the interpersonal communication, the lower the performance of the teacher. Thus the findings and facts and data in the analysis of this study further support the previous results of a positive relationship between interpersonal communication and teacher performance.

The result of hypothesis testing shows that there is a functional relationship between transformational leadership, job engagement, and interpersonal communication together with teacher performance with regression equation $\hat{\mathrm{Y}}=0.680+0.176 \mathrm{X}_{1}+0.179 \mathrm{X}_{2}+0.483 \mathrm{X}_{3}$. This shows a positive relationship between transformational leadership, job engagement, and interpersonal communication together with teacher performance.

The coefficient of determination between transformational leadership, job engagement, and interpersonal communication together with teacher performance is 0.498 . This means that $49.8 \%$ teacher performance is the result of the workings of transformational leadership, engagement, and interpersonal communication variables altogether, while $50.2 \%$ is contributed by other variables that are related to teacher performance improvement.

The above quantitative data is reinforced by the observation data on qualitative research which has conclusions about transformational leadership, job engagement, and interpersonal communication together has a positive relationship with teacher performance.

This is consistent with the theory, According to Angelo Kinicki and Brian K. Williams (2008), that transformational leadership is a leadership that transforms employees to pursue organizational goals beyond personal interests. The transformational leader will seek to influence, move, and develop his leadership to others. According to TW Britt, JM Dickinson, TMG Shortridge, and ES McKibben (2007) job involvement focus on the extent to which work is related to a person's self-image, leading to engagement in which a person invests in a job, involving cognitive, emotional, and investment 
physical in work. As well as Gibson, et al. (2006) suggests interpersonal communication is the main way in managerial communication in one day. Usually, more than a quarter of managerial communication occurs face to face.

Previous relevant research on Transformational leadership by Lulus Triwahyuni, Thamrin Abdullah and Widodo Sunaryo (2014) and on work involvement by Muhammad Rizwan, Dil Jan Khan and Fawad Saboor (2011) as well as interpersonal communication by A. Kadir, Bibin Rubini, and Thamrin Abdullah (2016) which has been presented in the previous discussion. Thus it is concluded that these relevant researchers strengthen the results of current research.

The focus of qualitative research on transformational leadership, job engagement, and interpersonal communication together show active and significant results with the teacher performance that can be seen from the phenomenon of a healthy learning environment and supported by high awareness in realizing the performance of teachers who involved in a joint decision.

Thus, great transformational leadership, work engagement, and interpersonal communication together will be able to improve teacher performance.

\section{CONClusion}

The research results on the sequential explanatory analysis of teacher performance regarding transformational leadership, job engagement, and interpersonal communication of private high school teachers in Bogor City, Indonesia can be delivered as follows:

1. There is a very significant positive relationship between transformational leadership with teacher performance indicated by the value of correlation coefficient $=0.801$ and the coefficient of determination $=0.641$ which means that the contribution of transformational leadership on teacher performance of $64.1 \%$.

2. There is a very significant positive relationship between the involvement of work with teacher performance indicated by the correlation coefficient $=0.706$ and the coefficient of determination $r$ $=0.498$ which means that the contribution of job involvement to teacher performance of $49.8 \%$.

3. There is a very significant positive relationship between interpersonal communication with teacher performance indicated by the value of correlation coefficient of $=0.755$ and the coefficient of determination of $=0.57$ which means that the contribution of interpersonal communication to teacher's performance by $57 \%$.

4. There is a very significant positive relationship between transformational leadership, job engagement and interpersonal communication together with teacher performance indicated by the value of correlation coefficient $=0.706$ and coefficient of determination $=0.498$ which means that the contribution of transformational leadership, job engagement, and interpersonal communication together with teacher's performance of $49.8 \%$. The functional relationship between transformational leadership, job engagement and interpersonal communication together with teacher performance is indicated by the regression equation $\hat{y}=0.680+0.176 \mathrm{X}_{1}+0.179 \mathrm{X}_{2}+$ $0.483 \mathrm{X}_{3}$.

\section{REFERENCES}

[1] Kadir, Bibin Rubini, Thamrin Abdullah. The Effect of Organizational Culture, Interpersonal Communication, Work Motivation to Teacher's Performance. International Journal of Managerial Studies and Research (IJMSR) Volume 4, Issue 3, March 2016

[2] Angelo Kinicki dan Brian K. Williams. Management A Practical Introduction. New York: Mc Grow Hill. 2008.

[3] Bass Bernard M. dan Ronald E. Riggio. Transformational Leadership. London: New Jersey. 2006

[4] Gibson, James. John M Ivancevich, James H Donelly, Jr and Robert Konopaske, Organizations Behavior Structure Processes. New York: McGraw-Hill Companies, Inc. 2006.

[5] Lulus Triwahyuni, Thamrin Abdullah, dan Widodo Sunaryo, The Effect of Organizational Culture, Transformational Leadership and Self-Confidence to Teachers' Performance. International Journal of Managerial Studies and Research (IJMSR) Volume 2, Issue 10, November 2014.

[6] Muhammad Rizwan. Relationship of Job Involvement with Employee Performance: Moderating role of Attitude. European Journal of Business and Management ISSN 2222-1905 Vol. 3, No.8, 2011. 
Analysis of Sequential Explanatory of Teacher's Performance Reviewed from Transformational Leadership, Job Engagement, and Interpersonal Communication

[7] Sugiono, Cara Mudah menyusun Skripsi, Tesis dan Disertasi.Bandung: Alfabeta CV, 2013.

[8] Stephen P. Robbins and Timothy A. Judge. Organizations Behavior. $15^{\text {th }}$ edition. New York: Pearson Education, Inc. 2013.

[9] Steven L. Mc.Shane and Mary Ann Von Glinow. Organizational Behavior Emerging Knowledge and Practice for the Real World.New York: Mc Grow Hill. 2010.

[10] T. W. Britt, J. M. Dickinson, T. M. G. Shortridge, and E. S. McKibben: "Self-Engagement at Work," in D. L. Nelson and C. L. Cooper (Eds.). Positive Organizational Behavior. London: Sage Publications

Citation: Kun Nurachadijat, Soewarto Hadhienata, Widodo Sunaryo. "Analysis of Sequential Explanatory of Teacher's Performance Reviewed from Transformational Leadership, Job Engagement, and Interpersonal Communication" International Journal of Managerial Studies and Research (IJMSR) vol 4, no. 9, 2017, pp. 24-29. doi:http://dx. doi.org/10.20431/2349-0381.0509005.

Copyright: (C) 2017 Authors. This is an open-access article distributed under the terms of the Creative Commons Attribution License, which permits unrestricted use, distribution, and reproduction in any medium, provided the original author and source are credited. 